\title{
The C-terminal module IV of connective tissue growth factor is a novel immune modulator of the Th17 response
}

Raquel Rodrigues-Díez ${ }^{1}$, Raúl R Rodrigues-Díez ${ }^{1}$, Sandra Rayego-Mateos , Beatriz Suarez-Alvarez ${ }^{1}$, Carolina Lavoz ${ }^{1}$, Luiz Stark Aroeira ${ }^{2}$, Elsa Sánchez-López ${ }^{3}$, Macarena Orejudo ${ }^{1}$, Matilde Alique ${ }^{1}$, Carlos Lopez-Larrea ${ }^{4}$, Alberto Ortiz ${ }^{5}$, Jesús Egido ${ }^{6}$ and Marta Ruiz-Ortega ${ }^{1}$

Connective tissue growth factor (CTGF/CCN2) is a matricellular protein susceptible to proteolytic degradation. CCN2 levels have been suggested as a potential risk biomarker in several chronic diseases. In body fluids, CCN2 full-length and its degradation fragments can be found; however, their in vivo effects are far from being elucidated. CCN2 was described as a profibrotic mediator, but this concept is changing to a proinflammatory cytokine. In vitro, CCN2 full-length and its C-terminal module IV (CCN2(IV)) exert proinflammatory properties. Emerging evidence suggest that Th17 cells, and its effector cytokine IL-17A, participate in chronic inflammatory diseases. Our aim was to explore whether CCN2(IV) could regulate the Th17 response. In vitro, stimulation of human naive CD4 ${ }^{+}$T lymphocytes with CCN2(IV) resulted in differentiation to Th17 phenotype. The in vivo effects of CCN2(IV) were studied in C57BL/6 mice. Intraperitoneal administration of recombinant CCN2(IV) did not change serum IL-17A levels, but caused an activation of the Th17 response in the kidney, characterized by interstitial infiltration of Th17 (IL17A $\left.{ }^{+} / \mathrm{CD}^{+}\right)$cells and upregulation of proinflammatory mediators. In CCN2(IV)-injected mice, elevated renal levels of Th17-related factors (IL-17A, IL-6, STAT3 and ROR $\gamma$ t) were found, whereas Th1/Th2 cytokines or Treg-related factors (TGF- $\beta$ and Foxp-3) were not modified. Treatment with an anti-IL-17A neutralizing antibody diminished CCN2(IV)-induced renal inflammation. Our findings unveil that the C-terminal module of CCN2 induces the Th17 differentiation of human Th17 cells and causes a renal Th17 inflammatory response. Furthermore, these data bear out that IL-17A targeting is a promising tool for chronic inflammatory diseases, including renal pathologies.

Laboratory Investigation (2013) 93, 812-824; doi:10.1038/labinvest.2013.67; published online 6 May 2013

KEYWORDS: CCN2/ IL-17A; inflammation; TGF- $\beta$; Th17 cells

Connective tissue growth factor (CTGF/CCN2) is a cysteinerich secreted matricellular protein that exerts many biological functions depending on the cellular context. ${ }^{1} \mathrm{CCN} 2$ is a $36-38 \mathrm{kDa}$ monomeric protein composed of 349 residues. This protein has a modular architecture comprising four functional modules: an amino-terminal insulin-like growthfactor-binding domain (IGFB), the cysteine-rich domain (also called von Willebrand type $\mathrm{c}$ domain), a thrombospondin type 1 repeat domain, and the C-terminal heparin-binding domain (Module 4) also known as a carboxy-terminal cystine knot domain (namely here CCN2(IV)). ${ }^{2}$ Between modules
2 and 3 is the 'hinge region' that is cleaved by most proteases, including matrix metalloproteases (MMPs) 1, 2, 3, 7, 9, and 13, elastase, and plasmin, the latter two of which also cleave the individual modules to yield four fragments. ${ }^{3}$ In particular, MMP2 clips CCN2 in vitro to a $10-\mathrm{kDa}$ fragment and that both full-length and clipped CCN2 were recovered from fibroblast cell culture supernatants. ${ }^{1}$ In biological fluids, CCN2 can be found in various forms: full-length molecule, fragments including $\mathrm{N}$-terminal and C-terminal halves cleaved in the 'hinge region,' as well as the individual $10-12 \mathrm{kDa}$ that corresponds to $\mathrm{CCN} 2(\mathrm{IV}){ }^{1,4}$

\footnotetext{
${ }^{1}$ Cellular Biology in Renal Diseases Laboratory, Instituto de Investigacion Sanitaria Fundación Jiménez Díaz, Universidad Autónoma Madrid, Madrid, Spain; ${ }^{2}$ Servicio de Nefrología, Hospital Universitario La Paz- IdiPAZ, Madrid, Spain; ${ }^{3}$ Translational Oncology Unit, Instituto de Investigaciones Biomédicas 'Alberto Sols,' CSIC, Madrid, Spain; ${ }^{4}$ Department of Immunology, Hospital Universitario Central de Asturias, Oviedo, Spain; ${ }^{5}$ Dialysis, Fundación Jiménez Díaz, Madrid, Spain and ${ }^{6}$ Renal Research Laboratory, Fundación Jiménez Díaz, Madrid, Spain

Correspondence: Dr M Ruiz-Ortega, PhD, Cellular Biology in Renal Diseases Laboratory, Instituto de Investigación Fundación Jiménez Díaz, Universidad Autónoma Madrid, Avda, Reyes Católicos, 2, 28040 Madrid, Spain. E-mail:mruizo@fjd.es

Received 3 May 2012; revised 4 April 2013; accepted 8 April 2013
} 
These variations produce a subfamily of secreted proteins with distinct functions. However, the biological in vivo effects of CCN2 and its fragments are still unknown. Several independent studies have evaluated CCN2 levels in the urine and/or serum in several chronic kidney diseases. Some groups have found elevated levels of the full-length CCN2, ${ }^{5,6}$ or the N-terminal, ${ }^{6,7}$ or the C-terminal ${ }^{8-10} \mathrm{CCN} 2$ fragments determined by ELISA, using antibodies that recognized each part of the molecule. Based on these data, CCN2 has been proposed as a risk biomarker of human diabetic nephropathy and other forms of chronic kidney disease, ${ }^{2,5-10}$ and for cardiac dysfunction in patients exhibiting myocardial fibrosis and chronic heart failure. ${ }^{11}$

CCN2 has been found overexpressed in almost all human disorders characterized by excessive scarring and fibrosis. ${ }^{2,12}$ The concept of CCN2 as a downstream mediator of profibrotic factors, including transforming growth factor- $\beta$ (TGF- $\beta$ ) and Angiotensin II, is the chief operating paradigm in the field. ${ }^{13,14}$ Therapeutic approaches that selectively block endogenous CCN2 activity have proven beneficial effects in fibrotic-related diseases, including experimental lung, liver, vascular, and renal diseases, and some authors have suggested that CCN2 could be a therapeutic target for fibrosis. ${ }^{12-16}$ However, cardiac CCN2 overexpression conferred cardioprotection in Angiotensin II-infused mice and in ischemia-reperfusion injury, ${ }^{17,18}$ showing that CCN2 exerts protective effects in some pathological settings. These data suggest that before using CCN2 blockers in humans, it is necessary to fully understand the in vivo biological functions of this protein and its fragments.

Although many authors have proposed that CCN2 overproduction plays a major role in pathways that lead to fibrosis, ${ }^{12}$ the direct contribution of CCN2 to fibrosis in vivo is still unclear. In contrast, in vitro studies support the novel concept of CCN2 as a proinflammatory cytokine. ${ }^{19}$ CCN2 is a chemotactic factor for immune cells,$^{20}$ has promoted cell adhesion and migration, and has upregulated proinflammatory factor production, including cytokines, chemokines, and adhesion molecules. ${ }^{19}$ We have previously demonstrated that systemic administration of CCN2(IV) elicited the recruitment of inflammatory cells in the murine kidney after $24 \mathrm{~h}$, suggesting that CCN2(IV) could induce acute inflammation in vivo, ${ }^{21}$ but there are no data on sustained inflammation. Several studies have investigated the biological functions of CCN2 modules. In vitro studies using recombinant proteins have shown that the full-length CCN2 and its C-terminal module IV (named here CCN2(IV)) increased matrix production, caused epithelial-tomesenchymal transition of tubular epithelial cells, and induced endothelial cell migration and proliferation, whereas the $\mathrm{N}$-terminal domain was not effective in these studies. ${ }^{22-24}$ In human renal fibroblasts, the $\mathrm{N}$-terminal domain binds IGF-I and enhances the induction of matrix components. ${ }^{25-27}$ Data from several laboratories support an important role for CCN2(IV) in the regulation of several process induced by other proteins, including mitosis, angiogenic activity, and heparin binding. ${ }^{4,28,29}$ These data show the complexity of this molecule.

The classical view of the immune response regulation based on Th1/Th2 paradigm of $\mathrm{T}$ helper (Th) cells has been enlarged by the discovery of novel subsets, including proinflammatory Th17 $\left(\mathrm{CD} 4^{+} / \mathrm{IL}^{-} 17 \mathrm{~A}^{+}\right)$cells and immunosuppressive $\mathrm{CD}^{+} / \mathrm{CD} 25^{\text {high }} / \mathrm{Foxp}^{+}$regulatory $\mathrm{T}$ cells (Tregs). ${ }^{30,31}$ Growing evidence suggests that IL-17A, the Th17 effector cytokine, besides participating in immunemediated diseases, is also involved in chronic inflammatory diseases such as atherosclerosis, and hypertension. ${ }^{30-33}$ Recent studies suggest that blockade of IL-17A is a promising tool for chronic human inflammatory diseases, as observed in rheumatoid arthritis, uveitis, and psoriasis. ${ }^{34-36}$ Our aim was to explore whether the CCN2(IV) could regulate the Th17 response and therefore contribute to persistent inflammation. First, we evaluated the direct effect of CCN2(IV) in human CD4 ${ }^{+} \mathrm{T}$ lymphocyte differentiation. Second, we investigated whether CCN2(IV) could regulate Th17 response in vivo using a model of systemic CCN2(IV) administration into mice.

\section{MATERIALS AND METHODS \\ Human T-Cell Isolation}

Human peripheral blood mononuclear cells (PBMCs) were obtained from peripheral blood of healthy donors (Blood Transfusion Center, Oviedo, Spain) after written informed consent and approval in accordance with the Declaration of Helsinki Principles. PBMCs were isolated by Ficoll-Hypaque density gradient centrifugation (Lymphoprep, Oslo, Norway). Naive $\mathrm{CD}^{+}{ }^{+} \mathrm{T}$ cells were subsequently isolated from PBMCs by negative selection using naive $\mathrm{CD} 4^{+} \mathrm{T}$ cell isolation Kit II (Miltenyi Biotec GmbH, Bergich Gladbach, Germany) according to the manufacturer's instructions. The purity of isolated cells was always $>95 \%$.

\section{In Vitro Th17 Polarization Cell}

Naive T-cell differentiation toward Th17 effector cells was performed as following. Isolated naive $\mathrm{CD}^{+} \mathrm{T}$ cells were cultured at a concentration of $5 \times 10^{5}$ cells $/ \mathrm{ml}$ in complete RPMI-1640 medium supplemented with $10 \%$ heatinactivated fetal calf serum (FBS) and $100 \mathrm{U} / \mathrm{ml}$ streptomycin-penicillin solution at $37{ }^{\circ} \mathrm{C}$ and $5 \% \mathrm{CO}_{2}$ in 48-well plates. For the experiments, cells were stimulated in Th17 cell polarizing medium containing $50 \mathrm{U} / \mathrm{ml}$ interleukin2 (IL-2), plate-bound anti-CD3 $(3 \mu \mathrm{g} / \mathrm{ml})$ and anti-CD28 $(3 \mu \mathrm{g} / \mathrm{ml})$, and neutralizing anti-IFN- $\gamma$ and anti-IL4 monoclonal antibodies ( $5 \mu \mathrm{g} / \mathrm{ml}$ each, eBiosciences, San Diego, CA, USA), and different stimuli were added ( $1 \mathrm{ng} / \mathrm{ml}$ TGF- $\beta$, $20 \mathrm{ng} / \mathrm{ml} \mathrm{IL-6,} 50 \mathrm{ng} / \mathrm{ml}$ CCN2(IV); supplied by Peprotech, NJ, USA). After 2 days, cells were restimulated with Th17 cell polarizing medium and stimuli, adding additionally $10 \mu \mathrm{g} / \mathrm{ml}$ IL-23 to each well. After 5 days, the Th17 phenotype was analyzed by flow cytometry. 


\section{Design of the Experimental Model}

Studies were performed in adult male C57BL/6 mice (9-12 weeks old, $20 \mathrm{~g}$; obtained from Harlan Interfauna Ibérica, S.A., Barcelona, Spain) and maintained at the local animal facilities, with free access to food and water, normal light/ dark cycles, and under special pathogen-free conditions. C57BL/6 mice received a single intraperitoneal injection of recombinant CCN2(IV) (corresponding to human CCN2 module 4 , a protein of 98A.A. residues and $11 \mathrm{kDa}$; purchased from Peprotech), at the dose of $2.5 \mathrm{ng} / \mathrm{g}$ of body weight, dissolved in saline, as described previously. ${ }^{21}$ The recombinant CCN2(IV) present endotoxin levels of $<0.01$, and the quality and purity was also confirmed by MALDI-TOF (data not shown). Mice were studied after 5, 10 , and 15 days ( $n=10$ mice in the 10-day group and 5 mice in the other groups). A control group with same volume of saline injection was also studied ( $n=10$ mice). To discard that CCN2(IV) inflammatory reaction was caused by transxeno differences in human/murine protein, the $\operatorname{IgM} / \operatorname{IgG}$ ratio was evaluated in mice serum (no differences between groups were found, data not shown).

The model of unilateral ureteral obstruction (UUO) was studied in male C57BL/6 mice. The model was performed under isofluorane-induced anesthesia; the left ureter was ligated with silk (4/0) at two locations and cut between ligatures to prevent urinary tract infection (obstructed kidney), as described previously. ${ }^{37} \mathrm{~A}$ control group of sham-operated mice was also studied ( $n=8$ mice per group).

For IL-17A neutralization studies, mice were injected with $100 \mu \mathrm{g} /$ mouse of anti-IL-17A neutralizing antibody or isotype K1 IgG control (eBiosciences, $n=5$ mice per group), based on previous studies, ${ }^{38}$ and starting $24 \mathrm{~h}$ before CCN2(IV) injection and every $72 \mathrm{~h}$ thereafter until the time of killing at 10 days.

Mice were killed under anesthesia (Ketamine-HCl/Xylazine- $\mathrm{HCl}$ ) and then the kidneys were perfused in situ with cold saline before removal. One kidney from each mouse was fixed in buffered formalin, embedded in paraffin, and used for immunohistochemistry. The other kidney was snapfrozen in liquid nitrogen for gene and protein studies. All the procedures on animals were performed according to the European Community and Instituto de Investigación Sanitaria Fundación Jiménez Díaz Animal Research Ethical Committee guidelines.

\section{Flow Cytometry}

For analysis of intracellular cytokine production, cultured human $\mathrm{CD} 4{ }^{+}$T cells were stimulated with PMA $(50 \mathrm{ng} / \mathrm{ml})$ and ionomycin $(1 \mu \mathrm{g} / \mathrm{ml}$; both from Sigma-Aldrich) in the presence of monensin (eBiosciences) for $6 \mathrm{~h}$. Following surface staining with APC-labeled anti-CD4 and PerCPCy5.5-labeled anti-CD3 (Biolegend, San Diego, CA, USA), cells were fixed and permeabilized using Fix and Perm reagent (eBiosciences). Furthermore, intracellular cytokine staining was performed with an anti-IL17A-PE antibody
(Biolegend). Isotype controls were used to define markers settings. In blood samples from mice models, circulating levels of T lymphocytes were evaluated. Cell surface staining was performed using FITC-labeled anti-CD3 and PE-labeled anti-CD4 (BD Pharmingen, San Diego, CA, USA). After cell surface staining, factor X-linked forkhead/winged helix (Foxp3) was stained using Foxp3 staining kit (BD Pharmingen) according to the manufacture's instructions. Samples were acquired on a BD FACScalibur ${ }^{\mathrm{TM}}$ Cytometer using the CellQuest Pro Software package (Becton Dickinson, Franklin Lakes, NJ, USA). The specific fluorescence intensity was quantified as the mean fluorescence intensity (MFI) calculated by subtracting the background of isotype-matched control staining from the total fluorescence.

\section{Renal Histology and Immunohistochemistry}

Paraffin-embedded sections were stained using standard histology procedures. Immunostaining was carried out in $3 \mu \mathrm{m}$ thick tissue sections that were deparafinized and antigen retrieved using the PT Link system (Dako Diagnósticos S.A, Barcelona, Spain) with Sodium Citrate Buffer (10 mM) adjusted to $\mathrm{pH} 6$ or $\mathrm{pH} 9$ depending on the immunohistochemical marker. Immunohistochemical staining was performed using the Dako Autostainer (Dako). Briefly, endogenous peroxidase was blocked and then sections were incubated for 30-20 min at room temperature with the following primary antibodies: mouse anti-CD4 (Dako, IS649) and rabbit anti-CD3 (Dako, IS503) ready to use, rat anti F4/80 (1/5000; Serotec, MCAP497), and rabbit anti-IL-17A (1:250; Abcam: ab9565). After washing, slides were treated with the EnVision ${ }^{\mathrm{TM}}$ DuoFLEX Doublestain System using 3,3'-diaminobenzidine as cromogen. For F4/80 staining, a rabbit anti-rat IgG antibody was used as linker before EnVision treatment. Sections were counterstained with Carazzi's hematoxylin. The total number of positive stained cells was quantified in five randomly chosen fields $(\times 200)$ using Image-Pro Plus software. Data are expressed as positive stained area $v s$ total analyzed area. Samples from each animal were examined in a blind manner.

Double immunofluorescence staining for CD4 and IL-17A was performed in OCT (Optimal Cutting Temperature, Sakura) embedded frozen sections. Before fixation (PFA 4\% $10 \mathrm{~min}$ at room temperature), slides were incubated for $1 \mathrm{~h}$ at room temperature with $4 \%$ of bovine serum albumin (BSA) and serum in $1 \times$ phosphate-buffered saline (PBS) to eliminate nonspecific protein binding sites. Primary antibody rabbit anti-IL-17A (1:250; Abcam: ab9565) was incubated overnight at $4{ }^{\circ} \mathrm{C}$. After washing, slides were treated with the corresponding anti-IgG Alexa488-conjugated secondary antibody (1:300). To determinate T-cell colocalization, antibody to CD4 was incubated overnight followed by an Alexa633-conjugated secondary antibody (1:300). Nuclei were contrasted with DAPI. Negative controls were incubated with a nonspecific immunoglobulin of the same isotype as the primary antibody and without primary antibody. 


\section{Protein Studies}

Kidney extracts were lysed in lysis buffer $(50 \mathrm{mM}$ Tris- $\mathrm{HCl}$, $\mathrm{pH} 7.4,150 \mathrm{mM} \mathrm{NaCl}, 2 \mathrm{mM}$ EDTA, $2 \mathrm{mM}$ EGTA, $0.2 \%$ Triton X-100, 0.3\% NP-40, $100 \mu \mathrm{M}$ phenylmethylsulphonylfluoride, $1 \mathrm{mM}$ dithiothreitol, $100 \mu \mathrm{M} \mathrm{Na} \mathrm{VO}_{4}$, and $1 \mathrm{mM}$ protease-inhibitor cocktail (Sigma)). Nuclear proteins were isolated as described previously. ${ }^{21}$ Protein concentration was determined by the BCA method (Pierce). Tissue protein extracts $(30 \mu \mathrm{g} /$ lane $)$ were separated on $8-12 \%$ polyacrylamide-SDS gels under reducing conditions. Samples were then transferred onto PVDF membranes (Bio-Rad, Alcobendas, Spain), blocked with 5\% nonfat dry milk, in TBS with $0.05 \%$ Tween-20, and incubated overnight at $4{ }^{\circ} \mathrm{C}$ with the primary antibodies, subsequently incubated with peroxidase-conjugated IgG (Amersham), and developed by ECL chemiluminiscence (GE Healthcare, Buckinghamshire, UK). Autoradiographs were scanned using the Gel Doc ${ }^{\mathrm{TM}}$ EZ imager and analyzed with the Image Lab 3.0 software (Bio-Rad).

The primary antibodies used were: Affinity Purified anti-mouse ROR $\gamma t$ (1:1000; eBiosciences: 14-6981), Affinity Purified anti-mouse/human/rat Foxp3 (1:1000; eBiosciences; 14-4774), rabbit anti-phospho-Stat3 (Tyr705, 1:1000; Cell Signaling; \#9131), and p65 NF- $\kappa \mathrm{B}$ subunit (C-20, 1:1000; Santa Cruz; sc-372). The efficacy of protein loading and transfer to membranes was assessed by incubation with mouse anti-GAPDH antibody (1:5000; Chemicon, MAB374). In renal protein extracts, cytokine levels were analyzed by ELISA (100 ng/ml). Interferon- $\gamma$ (IFN- $\gamma$ ), IL-4, IL-10, IL-17A, and TGF- $\beta$ protein levels were assayed by an ELISA kit from eBiosciences; IL-6, monocyte chemotactic protein-1 (MCP-1), and RANTES (Regulated upon Activation, Normal T-cell Expressed, and Secreted) from BD Bioscience. Cytokine levels were quantified by comparison with a standard curve and data were expressed as fold change over the mean of value of control mice levels.

\section{Gene Expression Studies}

Total RNA was isolated from renal samples with Trizol (Invitrogen, Groningen, The Netherlands). cDNA was synthesized using the High capacity cDNA Archive Kit (Applied Biosystems, Foster City, CA, USA) using $2 \mu \mathrm{g}$ of total RNA primed with random hexamer primers, following the manufacturer's instructions. Multiplex RT-PCR was performed using fluorogenic (FAM) primers designed by Assay-on-Demand ${ }^{\mathrm{TM}}$ gene expression products (Applied Biosystems): MCP-1: Mm00441242_m1, RANTES: Mm01302428_m1, monocyte chemotactic protein-1 receptor 2 (CCR2): Mm-99999051-gH, CXCL1 (GRO- $\alpha$ ): Mm04207460_ m1, $\alpha$-smooth muscle actin ( $\alpha$-SMA): Mm01546133_m1, Fibronectin: Mm01256734_m1, Type I Pro-Collagen: Mm00483888_m1, Vimentin: Mm00449208_m5. Data were normalized to eukaryotic ribosomic $18 \mathrm{~s}$ rRNA (4310893E) (VIC). IL-17A gene expression (sense 5'-GGACTC TCCACCGCAATGA- $3^{\prime}$ and antisense $5^{\prime}$-GACCAGGATCTCT TGCTGGA- $3^{\prime}$ ) was detected using SYBR Green Master Mix
(Applied Biosystems) and normalized with eukaryotic ribosomic 18s (sense 5'-CAGCTTTGCAACCATACTCCC-3' ${ }^{\prime}$, and antisense $5^{\prime}$-CCGTCGTAGTTCCGACCATAA- $3^{\prime}$ ). The mRNA copy numbers were calculated for each sample by the instrument software using Ct value ('arithmetic fit point analysis for the lightcycler'). Results were expressed in copy numbers, calculated relative to control mice, after normalization against $18 \mathrm{~s}$.

\section{Statistical Analysis}

Statistical analysis was done using the SPSS statistical software (version 11.0, Chicago, IL, USA). After Kolmogorov-Smirnov test, which determined the nonnormal sample distribution of the data, differences between groups were assessed by Mann-Whitney $U$-test. Differences were considered significant when $P<0.05$.

\section{RESULTS \\ CCN2(IV) Induced Th17 Differentiation of Human Naive CD4 ${ }^{+}$T Cells}

Depending on cytokine environment, human naive CD4 ${ }^{+}$ $\mathrm{T}$ cells can differentiate into different Th effector subsets. IL-6 is an indispensable factor that generates Th17 cells from naive $\mathrm{T}$ cells ${ }^{31}$ through activation of the retinoic acidrelated orphan receptor- $\gamma \mathrm{t}(\mathrm{ROR} \gamma \mathrm{t})$ and signal transducer and activator of transcription 3 (STAT3). ${ }^{39,40}$ In vitro stimulation of isolated human naive CD $4^{+} \mathrm{T}$ cells, in Th17 cell polarizing conditions as described in the Materials and Methods section, with IL- 6 or CCN2(IV) for 5 days induced a significant increase in the number of IL-17A ${ }^{+}$-producing $\mathrm{CD}^{+} \mathrm{T}$ cells ( Th17 cells, determined by flow cytometry) compared with unstimulated cells in the same cultured conditions (Figures 1a and b). In CCN2(IV)-treated CD4 ${ }^{+} \mathrm{T}$ cells, elevated levels of phosphorylated STAT-3 were found (Figure 1c), showing that CCN2(IV) regulates this molecular mechanism involved in Th17 differentiation.

\section{CCN2(IV) In Vivo Administration in Mice Did Not Modulate Circulating IL-17A Levels}

In murine models of inflammatory diseases, including multiple sclerosis, inflammatory bowel disease, and arthritis, serum IL-17A levels are elevated, and the Th17 cell population is expanded and plays a pathogenic role; ${ }^{30}$ therefore, we first evaluated whether systemic administration of CCN2(IV) in mice could regulate circulating IL-17A levels. However, in CCN2(IV)-injected mice, plasma IL-17A levels were not modified at any time point studied (5, 10, and 15 days; Table 1), and remained at similar levels to control mice. Moreover, the total number of circulating $\mathrm{CD} 4{ }^{+}$cells were not changed between groups (evaluated flow cytometry, data not shown). Our data suggest that CCN2(IV) in vivo did not induce an expansion of systemic murine Th17 cells, the main cells responsible for circulating IL-17A levels, at least in the conditions of our study. 

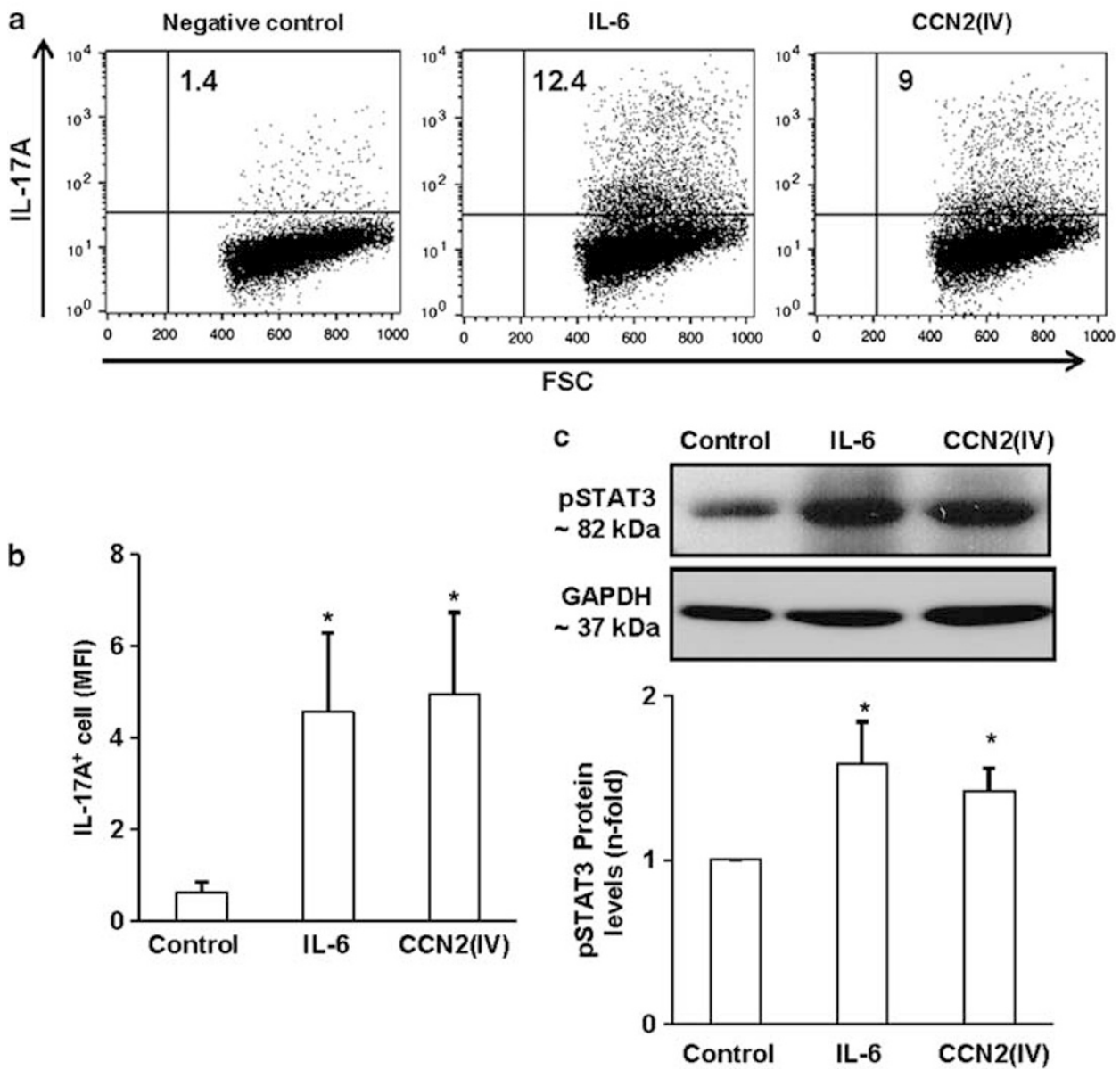

Figure $1 \mathrm{CCN}$ (IV) in vitro induced Th17 differentiation of human naive CD4 ${ }^{+} \mathrm{T}$ cells. Naive $\mathrm{CD} 4^{+} \mathrm{T}_{\text {cells }}$ were isolated from PBMCs. $5 \times 10^{5}$ cells/ml were incubated in Th17 cell polarizing medium (containing IL-2, anti-CD3, anti-CD28, neutralizing anti-IFN- $\gamma$, and anti-IL4) in the presence or absence of different stimuli $(20 \mathrm{ng} / \mathrm{ml} \mathrm{IL-6}$ or $50 \mathrm{ng} / \mathrm{ml} \mathrm{CCN2(IV))} \mathrm{for} 5$ days. Intracellular IL-17A staining was evaluated by flow cytometry and expressed as mean fluorescence intensity (MFI) calculated by subtracting the background of isotype-matched control staining from the total fluorescence. (a) Dot plots show a representative experiment of the induced IL-17A expression on gated CD4 ${ }^{+} T$ cells after stimulation with IL-6 or CCN2(IV) cytokines, and without stimulation. (b) The percentage of $\mathrm{CD}^{+}{ }^{+} \mathrm{T}$ cells expressing IL-17A cells (mean \pm s.e.m. of six experiments done) is shown. (c) Activation of STAT-3 was evaluated by levels of phosphorylated STAT3 in cellular extracts. A representative western blot experiment and data as mean \pm s.e.m. as fold change over control of four experiments. ${ }^{*} P<0.05$ vs control.

Table 1 IL-17A serum levels in CCN2(IV)-injected mice

\begin{tabular}{lcc}
\hline group & IL-17A serum levels & $P$-value vs control \\
\hline Control & $32.5 \pm 8.4$ & \\
CCN2(IV), 5 days & $30.5 \pm 2.0$ & 1 \\
CCN2(IV), 10 days & $26.7 \pm 4.1$ & 0.905 \\
CCN2(IV), 15 days & $34.5 \pm 7.2$ & 0.841 \\
\hline
\end{tabular}

C57BL/6 mice received a single i.p. injection of $2.5 \mathrm{ng} / \mathrm{g}$ body weight recombinant CCN2(IV) and were killed after 5,10 , or 15 days $(n=5,10$, and 5 mice per group, respectively) compared with control group (i.p. vehicle (saline), $n=10$ ). Data are expressed in $\mathrm{pg} / \mathrm{ml}$ as mean \pm s.e.m. of 5 to 10 mice per group.

\section{CCN2(IV) Induced an Activation of the Th17 Response in the Kidney}

Next, we evaluated whether CCN2(IV) could modulate the Th17 response at tissue levels. CCN2(IV) in vivo induced an inflammatory response in the murine kidney after $24 \mathrm{~h},{ }^{21}$ but there were no data at longer times. The involvement of a specific Th response activation can be determined by the evaluation of Th hallmark cytokines (Th1, Th2, Th17, and Treg cell-related cytokines: IFN- $\gamma$, IL-4, IL-17A, and TGF- $\beta 1 /$ IL-10, respectively). We have previously observed that after $24 \mathrm{~h}, \mathrm{CCN} 2$ (IV) increased renal levels of IFN- $\gamma$ and IL-4, downregulated IL-10, and did not change IL-17A renal levels. ${ }^{21}$ After 5 days, a slight upregulation of renal levels of all 


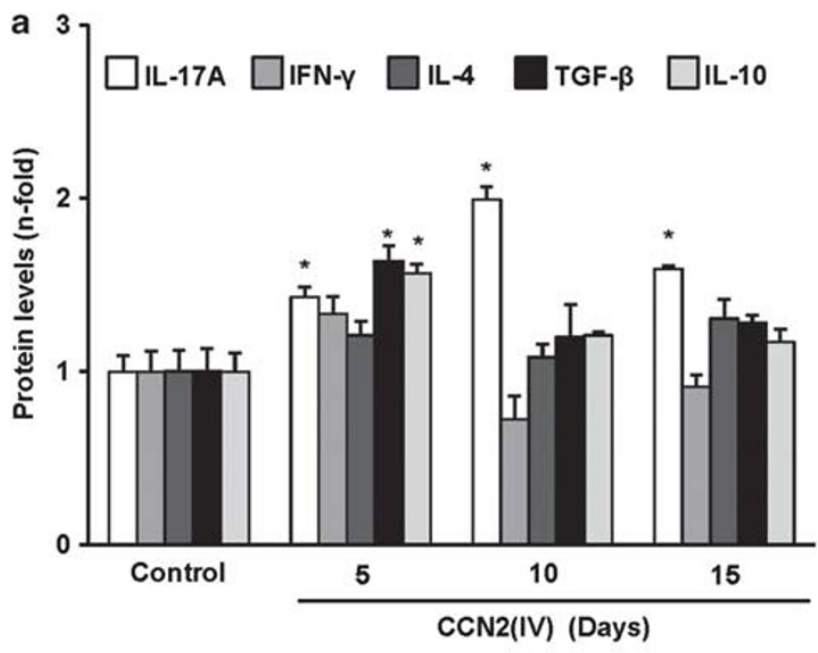

b

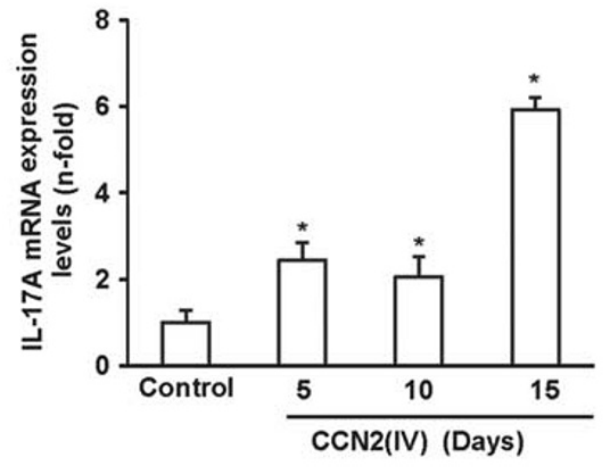

c

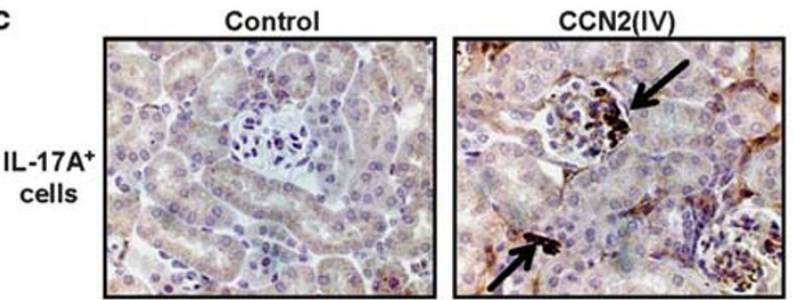

Figure 2 CCN2(IV) in vivo upregulated the Th17 hallmark cytokine IL-17A in the kidney, whereas it did not change renal levels of Th1, Th2, or Treg-related cytokines. C57BL/6 mice received a single i.p. injection of $2.5 \mathrm{ng} / \mathrm{g}$ body weight recombinant CCN2(IV) or vehicle (saline) and were killed after 5,10 , or 15 days ( $n=5,10$, and 5 mice per group, respectively) compared with control group (vehicle; $n=10$ ). (a) Renal protein levels of IL-17A, IFN- $\gamma$, IL-4, IL-10, and TGF- $\beta$ (Th17, Th1, Th2, Treg, and hallmark cytokines) analyzed by ELISA and expressed as fold change over control of mean \pm s.e.m. (10 to 5 animals per group). ${ }^{*} P<0.05$ vs control. (b) Total kidney RNA was isolated and IL-17A mRNA expression was evaluated by real-time PCR. Results are expressed as fold change over control of mean \pm s.e.m. (5 to 10 animals per group). ${ }^{*} P<0.05$ vs control. (c) Immunolocalization of IL-17A in the kidney of CCN2(IV)-treated mice. (a) IL-17A immunostaining in control and CCN2(IV)-treated mice, studied after 10 days, as a representative image of 5 mice per group, analyzed in independent experiments. Arrows mark positive IL-17A-expressing cells ( $\times 400$ magnification).

cytokines was observed in CCN2(IV)-injected mice (Figure 2a). Importantly, only IL-17A remained elevated at 10 and 15 days of CCN2(IV) administration (Figure 2a), as confirmed by real-time PCR (Figure 2b). These findings show that CCN2(IV) promotes a dynamic Th differentiation process in the kidney. Moreover, positive IL-17A staining was found in glomerular and tubulointerstitial areas of CCN2(IV)-injected mice after 10 days (immunohistochemistry), whereas no IL-17A expression was observed in control mice kidneys (Figure 2c). Our data clearly demonstrated that CCN2(IV) in vivo increased renal production of IL-17A, whereas Th1/Th2/Treg-related cytokines were not changed.

In the present study, at all time points evaluated $(5,10$, and 15 days), CCN2(IV)-treated mice had a significant increase in the number of $\mathrm{F} 4 / 80^{+}$cells (that mainly recognizes monocytes/macrophages) and $\mathrm{CD}^{+}$and $\mathrm{CD}^{+}{ }^{+} \mathrm{T}$ lymphocytes, compared with controls (Figures $3 \mathrm{a}$ and $\mathrm{b}$ ). To detect Th17 cells, double immunostaining using antibodies against IL-17A and CD4 was performed (Figure 3c). After 10 days of CCN2(IV) administration, IL-17A ${ }^{+} / \mathrm{CD} 4^{+}$cells were observed, demonstrating the presence of Th17 cells in the kidney in response to CCN2(IV). However, some

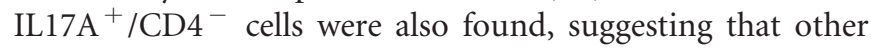
cells besides Th17, probably tubular epithelial cells as described previously, ${ }^{41}$ can produce IL-17A.

The regulation of inflammatory cell infiltration in the kidney is controlled by the local production of chemokines such as MCP-1 and RANTES, the main factors involved in the recruitment of macrophages and $\mathrm{T}$ lymphocytes, respectively. ${ }^{42}$ Among the intracellular signaling systems involved in the pathogenesis of renal inflammation, the activation of the NF- $\kappa \mathrm{B}$ pathway has special interest. ${ }^{43}$ In CCN2(IV)-treated mice, elevated renal mRNA and protein levels of MCP-1 and RANTES were found at all time points studied (real-time PCR and ELISA; Figures $4 \mathrm{a}$ and b). Moreover, in renal nuclear protein extracts of CCN2(IV)treated mice, elevated levels of p65 NF- $\kappa \mathrm{B}$ subunit were observed as compared with controls (Figure 4c), demonstrating renal NF- $\kappa \mathrm{B}$ activation.

In contrast, CCN2(IV) administration in mice did not induce any significant change in renal function or induction of proteinuria as compared with controls (data not shown). The evaluation of profibrotic-related genes showed a transient upregulation of $\alpha$-SMA (a marker of activated fibroblasts) and some extracellular matrix proteins, including fibronectin and procollagen, after 5 days of CCN2(IV) injection, which were downregulated thereafter (Figure 5). Moreover, there were no changes in renal morphology and collagen content (determined by Masson Trichrome, not shown). Our experimental data show that CCN2(IV) in vivo induced a sustained inflammatory response in the kidney, characterized by local production of IL-17A, but not fibrosis or kidney dysfunction.

\section{IL-17A Blockade Inhibited CCN2(IV)-Induced Renal Inflammatory Response}

To identify the role of IL-17A in the inflammatory response caused by CCN2(IV) at 10 days, a neutralizing IL-17A 
a
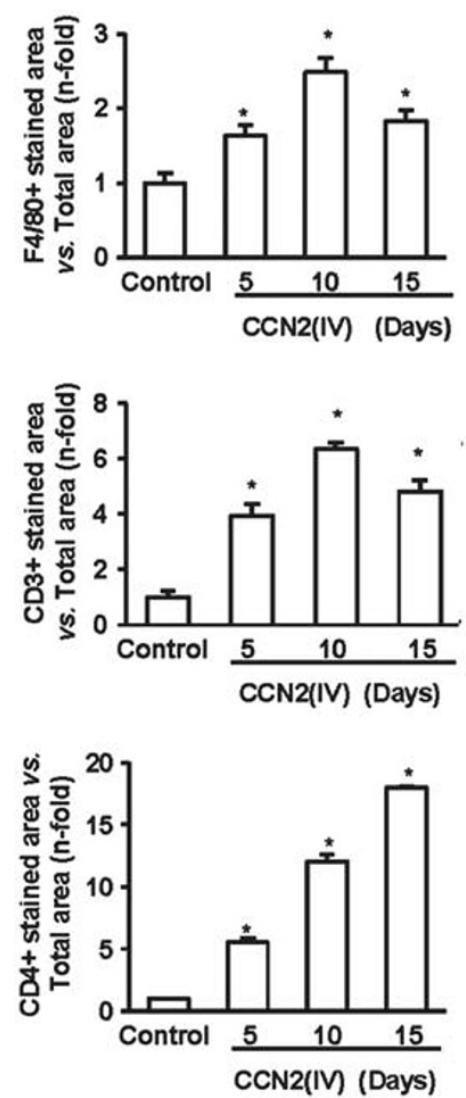

b
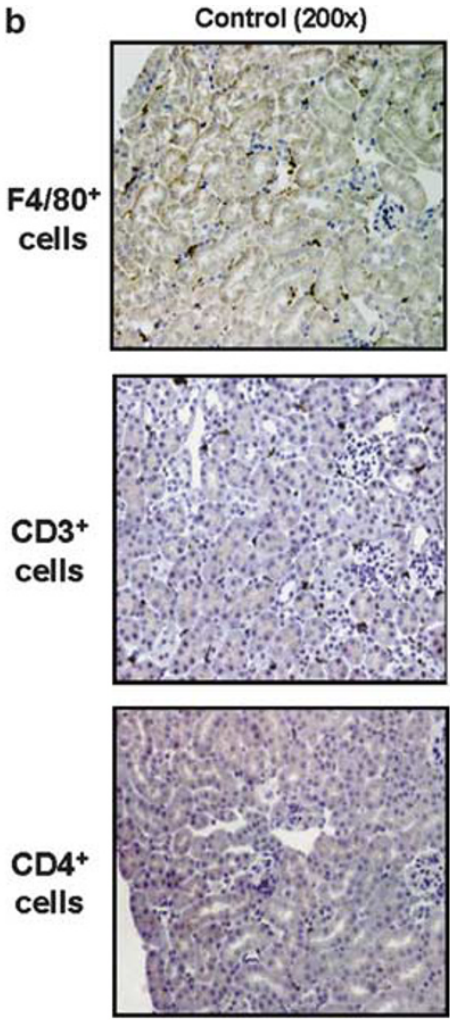

c
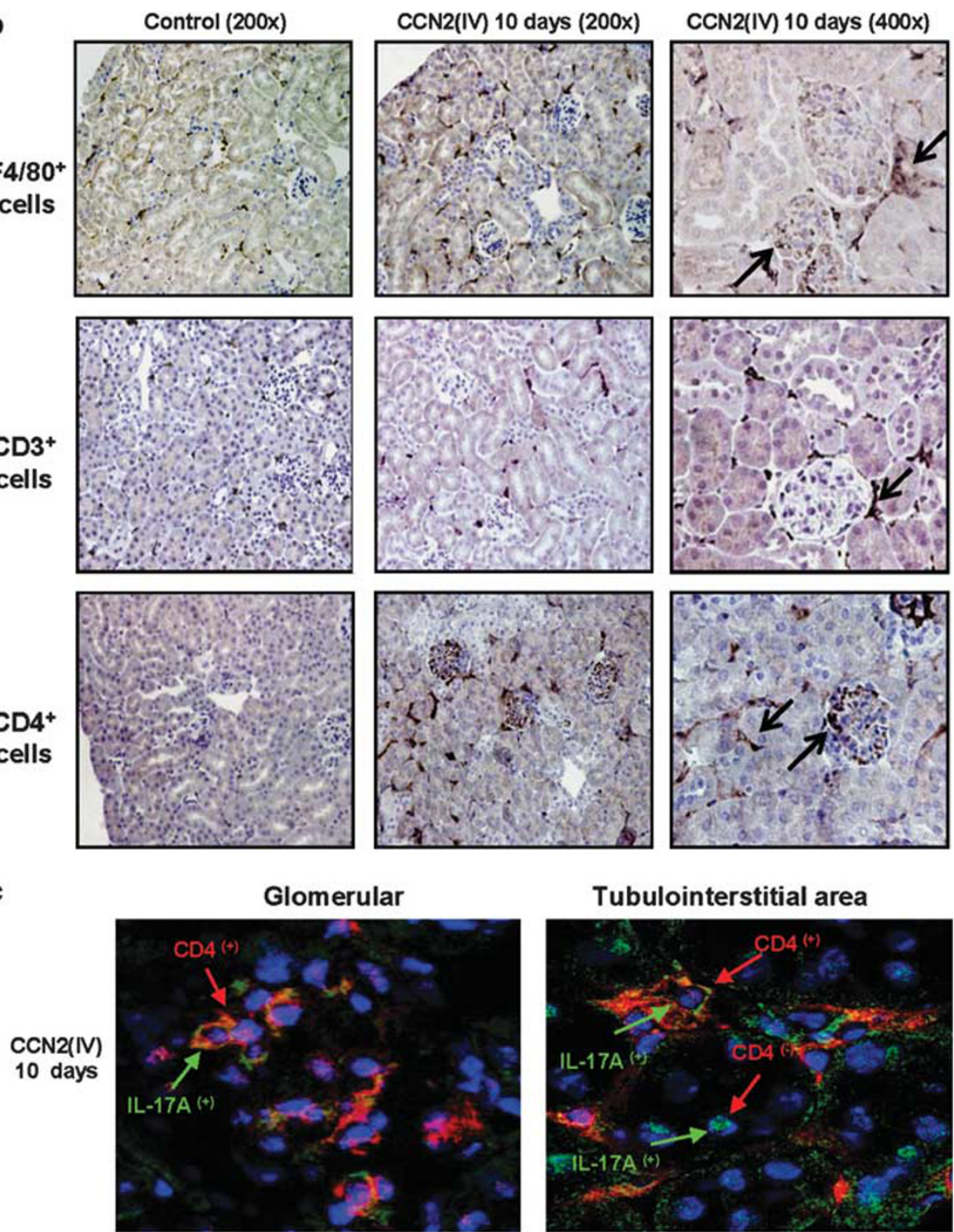

Tubulointerstitial area

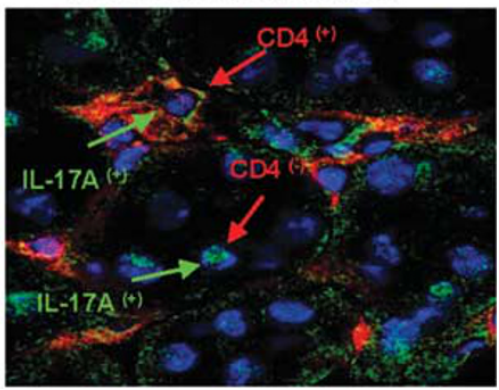

Figure 3 CCN2(IV) in vivo caused a sustained inflammatory cell infiltration in the kidney. C57BL/6 mice received a single i.p. injection of $2.5 \mathrm{ng} / \mathrm{g}$ body weight recombinant CCN2(IV) or vehicle (saline) and were killed after 5,10 , or 15 days $(n=5,10$, and 5 mice per group, respectively) compared with control group $(n=10)$. The inflammatory cell infiltration was characterized in paraffin-embedded renal sections by immunohistochemistry with anti-F4/80 (marker mainly of monocytes/macrophages), anti-CD3 (lymphocytes T marker), and anti-CD4 (effectors lymphocytes T marker) antibodies.

(a) The immunohistochemistry quantification expressed as mean \pm s.e.m. of fold change as compared with controls. ${ }^{*} P<0.01$ vs control group. (b) A representative animal from each group ( $\times 200$ magnifications). Arrows indicate infiltrating cells in detail ( $\times 400$ magnifications). (c) Confocal analysis of CCN2(IV)-treated renal samples showing double immunostaining of IL-17A ${ }^{+} / \mathrm{CD}^{+}{ }^{+}$cells (Th17 cells), both in glomeruli and tubulointerstitial areas. Some IL-17A ${ }^{+} / \mathrm{CD}^{-}$cells were observed in tubulointerstitial areas. Nuclei are in blue (DAPI staining; $\times 600$ magnification).

antibody was used. In CCN2(IV)-injected mice, IL-17A neutralization markedly decreased the number of infiltrating immune cells (macrophages and $\mathrm{CD}^{+}$and $\mathrm{CD}^{+}{ }^{+} \mathrm{T}$ lymphocytes) compared with IgG-treated mice (Figures $6 \mathrm{a}$ and b). Blockade of IL-17A significantly diminished renal CCN2(IV)-induced overexpression of MCP-1, RANTES, MCP-1 receptor (CCR2), and CXCL1 (Figure 6c). These data clearly demonstrate the involvement of IL-17A in CCN2(IV)mediated renal inflammation.

\section{CCN2(IV) Upregulated Th17-Related Factors in the Kidney}

Next, we explored whether CCN2(IV) regulates the upstream mechanisms involved in Th17 cell activation in the kidney. In CCN2(IV)-injected mice, renal IL-6 and ROR $\gamma \mathrm{t}$ protein levels were significantly increased compared with control mice (Figures 7a and b). Activation of STAT3, evaluated by increased levels of phosphorylated STAT3, was observed at 10 days after CCN2(IV) administration (Figure 7b). 
a

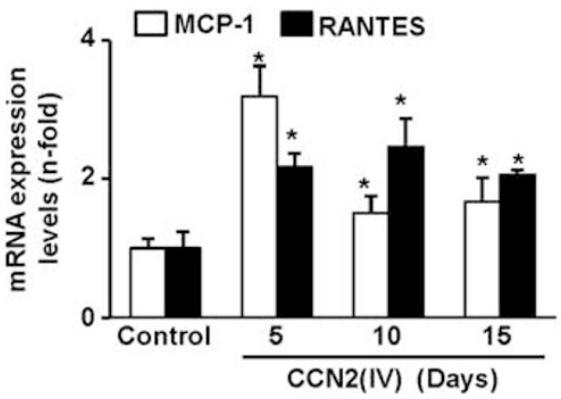

b

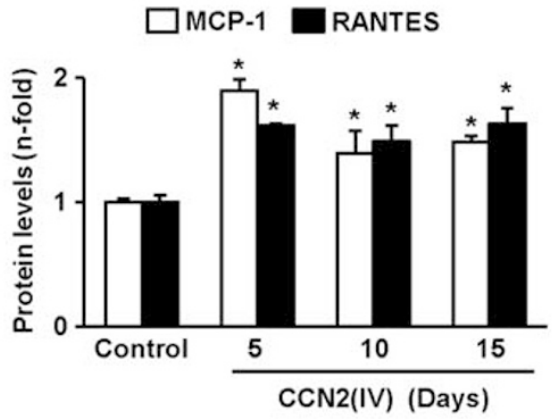

C
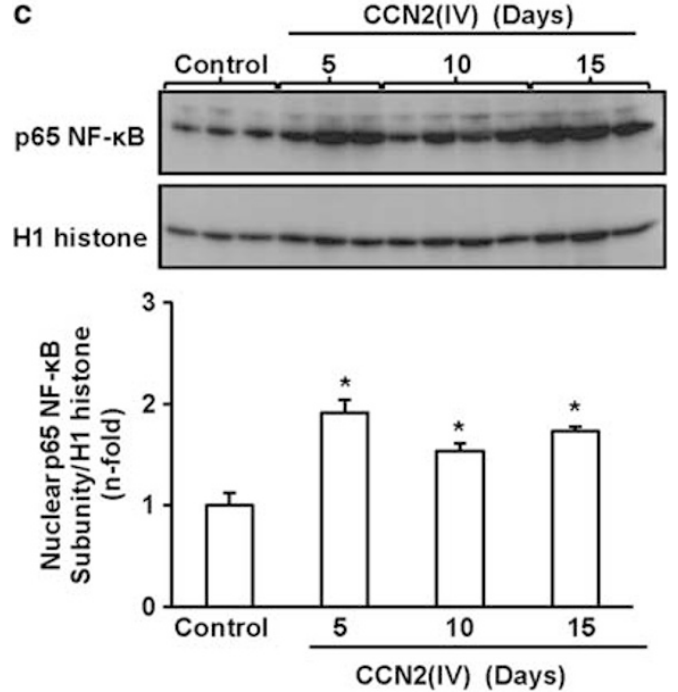

Figure 4 CCN2(IV) increased proinflammatory chemokine expression and activated NF- $\kappa$ B in the kidney. In renal samples from control and CCN2(IV)-injected mice for 5, 10, and 15 days, gene expression of MCP-1 and RANTES was evaluated by real-time PCR (a) and protein levels by ELISA (b). Activation of renal NF- $\kappa$ B was evaluated determining the nuclear levels of p65 NF- $\kappa$ B subunit by western blot (c). Data are expressed as $n$-fold increase over control as mean \pm s.e.m. of 5-10 animals per group. ${ }^{*} P<0.05$ vs control.

We have further evaluated whether CCN2(IV) could regulate Th17-related factors in cultured renal cells. Previous studies have demonstrated that CCN2(IV) increased IL-16 production in renal cells. ${ }^{21}$ In cultured renal cells, incubation with CCN2(IV) increased STAT3 phosphorylation, with a maximal response after $10 \mathrm{~min}$ of stimulation (Figure 7c).

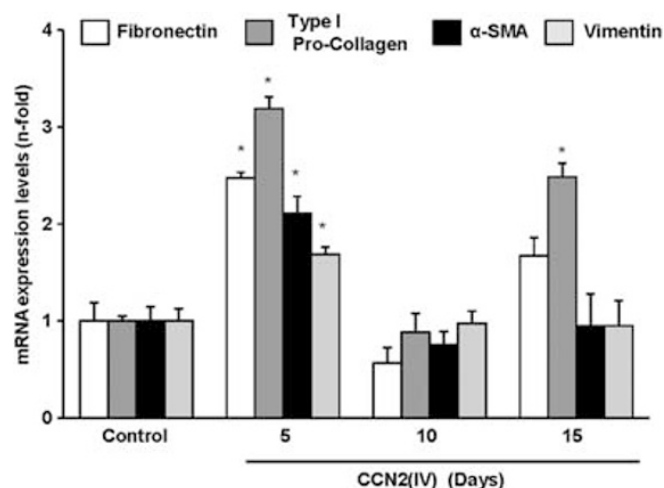

Figure 5 CCN2(IV) induced a transient upregulation of matrix-related proteins in the kidney. In renal samples from control and CCN2(IV)injected C57BL/ 6 mice for 5, 10, and 15 days, gene expression of fibronectin, type I collagen, $\alpha$-SMA, and vimentin was evaluated by realtime PCR. Data are expressed as $n$-fold increase over control as mean \pm s.e.m. of $5-10$ animals per group. ${ }^{*} P<0.05$ vs control.

\section{CCN2(IV) did not Regulate Treg-Related Transcription Factors in the Kidney}

Th17/Treg differentiation from naive $\mathrm{CD} 4^{+}$cells is a process closely regulated that depends on cytokine environment and activation of specific transcription factors. Treg cell differentiation is regulated through the activation of Foxp $3 .{ }^{44}$ In CCN2(IV)-injected mice, Foxp3 renal levels were not elevated compared with controls at all times studied (Figure 8a). Moreover, frequency of the $\mathrm{CD} 4^{+} / \mathrm{Foxp}^{+}$Treg circulating cells, assessed by flow cytometry, were not modified in response to CCN2(IV) administration (Figure 8b).

\section{Elevated Renal Levels of IL-17A in Nonimmune Experimental Models of Renal Damage Characterized by CCN2 Overexpression}

Previous studies have shown the involvement of Th17 cells in nonimmune inflammatory experimental renal injury, such as the model of UUO. ${ }^{45}$ In this model we have previously described elevated renal levels of CCN2 in the obstructed kidneys. ${ }^{37}$ Now, we have observed that obstructed kidneys also presented elevated levels of IL-17A as compared with controls (Figure 9), showing an association between CCN2 and IL-17A upregulation in experimental renal damage.

\section{DISCUSSION}

Our in vitro and in vivo studies support the novel concept of CCN2(IV) as a proinflammatory cytokine that is able to modulate the Th17 immune response. Our findings expand the known profibrogenic CCN2 signaling pathways to a true cytokine with an active role in sustained renal inflammation.

Our studies carried out on human $\mathrm{CD}^{+}{ }^{+} \mathrm{T}$ lymphocytes showed that CCN2(IV) drives Th17 differentiation. The differentiation of naive $\mathrm{CD} 4{ }^{+} \mathrm{T}$ cells into different Th effector subsets is a process closely regulated by specific cytokines and transcription factors. ${ }^{30,31,39,40}$ Stimulation of 

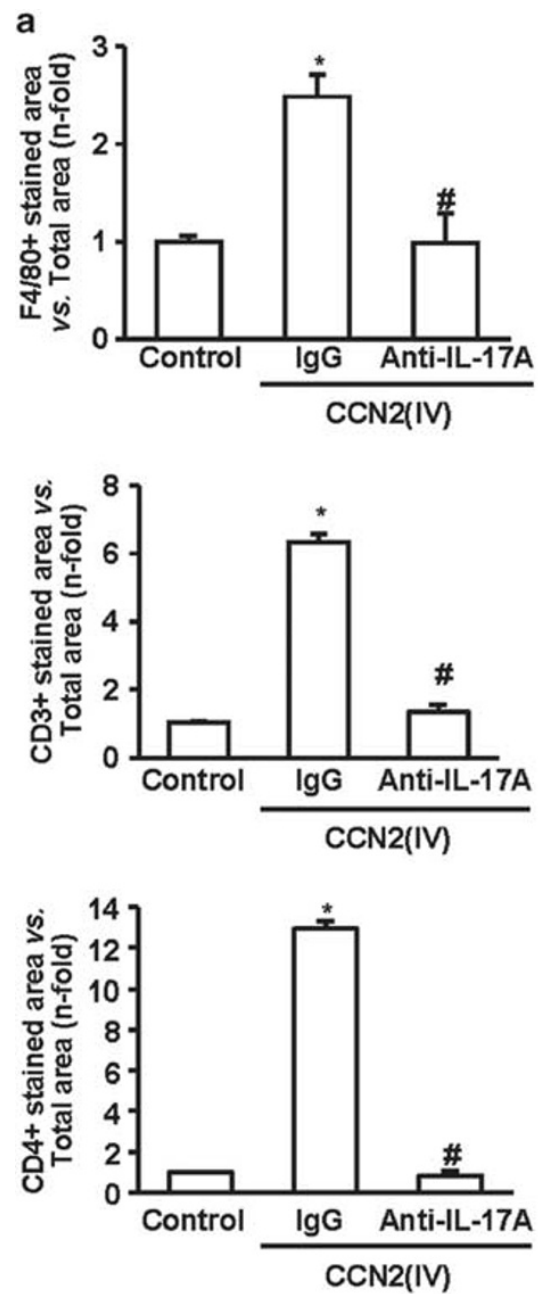

b
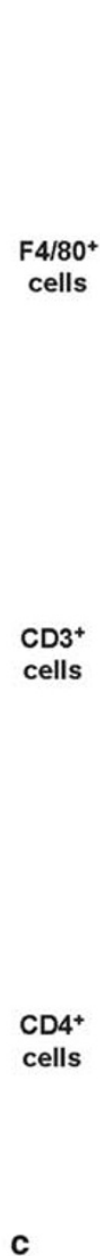

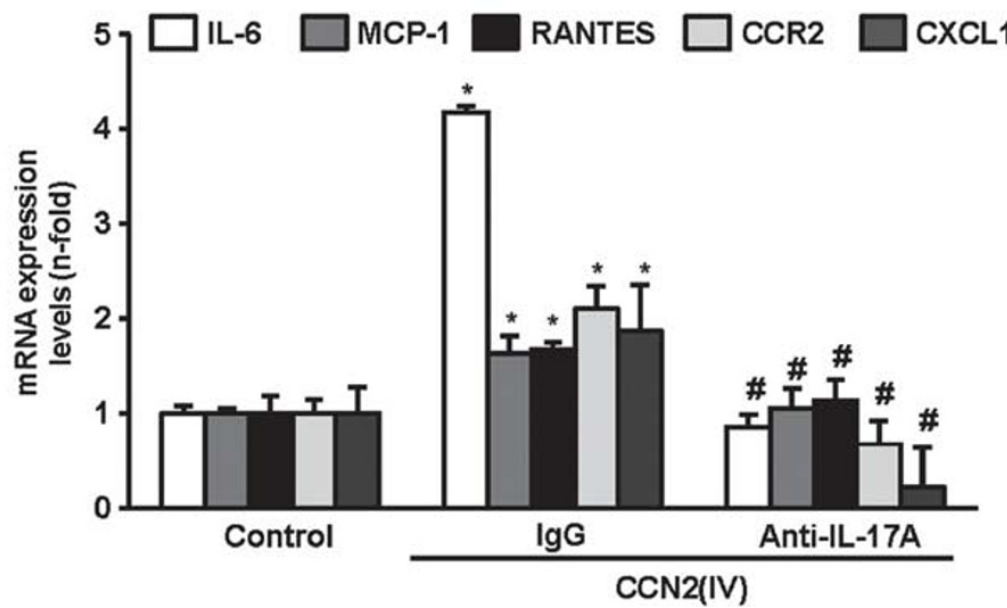

Figure 6 IL-17A blockade inhibited CCN2(IV)-induced renal inflammatory responses. To block IL-17A responses, mice were treated with an IL-17A neutralizing antibody or its corresponding IgG isotype as control ( $n=5$ mice per group) $24 \mathrm{~h}$ before CCN2(IV)) injection and every $72 \mathrm{~h}$ thereafter until the time of killing at day 10. IL-17A neutralization diminished renal inflammatory cell infiltration in CCN2(IV)-injected mice. (a) Quantification of F4/80-, CD3-, or CD4-positive cells, expressed as mean \pm s.e.m. fold change of positive staining vs total area over control. (b) Representative immunohistochemistry from each group ( $\times 200$ magnification). (c) IL-17A neutralization decreased CCN2(IV)-induced renal chemokine expression. IL-6, MCP-1, RANTES, CCR2, and CXCL1 mRNA expression as mean \pm s.e.m. analyzed by real-time PCR. ${ }^{*} P<0.05$ vs control; ${ }^{\sharp} P<0.05$ vs CCN2(IV)-IgG. 
a
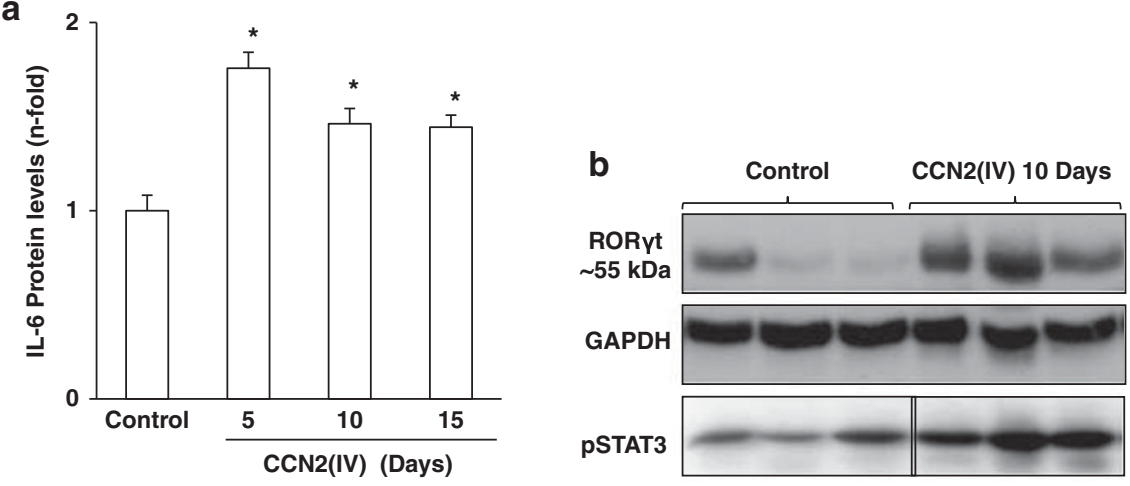

C
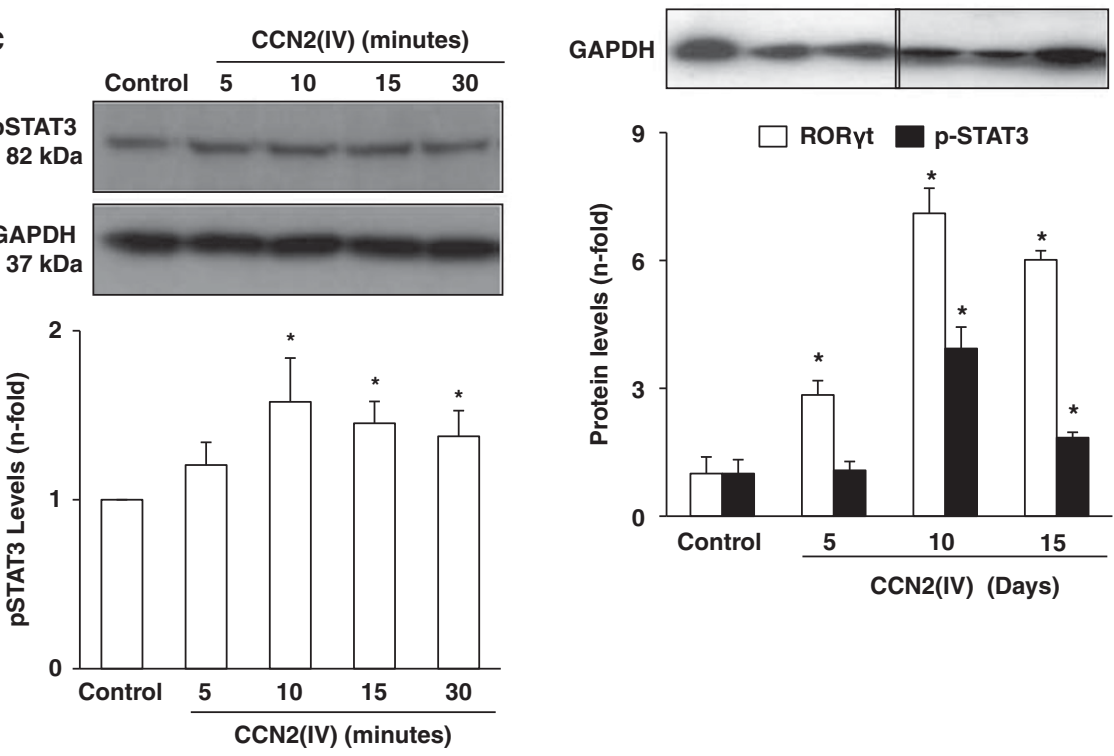

Figure 7 CCN2(IV) activated Th17-related factors in mice kidney. Renal protein levels of control and CCN2(IV)-injected mice for 5, 10, and 15 days were isolated. (a) Renal IL-6 levels evaluated by ELISA. The renal levels of Th17-related transcription factors ROR $\gamma$ t and phosphorylated STAT3 (p-STAT3) were analyzed by western blot. (b) Quantification of protein levels of 5 to 10 mice per group, and a representative western blot of control and CCN2(IV)treated mice killed at day 10. Data are expressed as mean \pm s.e.m. as fold change over control. ${ }^{*} P<0.05$ vs control. (c) Mice tubular epithelial cells were incubated with $10 \mathrm{ng} / \mathrm{ml} \mathrm{CCN2(IV)} \mathrm{until} 30 \mathrm{~min}$ and the phosphorylated levels of STAT-3 were evaluated by western blot. (c) A representative experiment of four experiments performed is shown, and data are expressed mean \pm s.e.m. ${ }^{*} P<0.05$ vs control.

isolated human naive $\mathrm{CD} 4{ }^{+} \mathrm{T}$ cells with $\mathrm{CCN} 2(\mathrm{IV})$ induced a Th17 cell polarization, characterized by increased IL-17A ${ }^{+}$/ $\mathrm{CD}^{+}{ }^{+} \mathrm{T}$ cells, similar to that observed with IL-6, a known inducer of Th17 differentiation. Th1 cell differentiation is controlled by T-bet and STAT4, Th2 is GATA-3/STAT6 dependent, Treg is Foxp-3 mediated, and Th17 depends on STAT3 activation and subsequent ROR $\gamma$ t induction. ${ }^{38-40}$ The importance of Th17-related factors have been demonstrated using knockout mice, where STAT3-null cells fail to express ROR $\gamma \mathrm{t},{ }^{39}$ and lack of ROR $\gamma \mathrm{t}$ results in profound Th17 deficiency. ${ }^{40}$ In vitro CCN2(IV) activated STAT-3 in isolated human naive $\mathrm{CD} 4{ }^{+} \mathrm{T}$ cells and in cultured renal cells. In vivo CCN2(IV) upregulated Th17-related factors in the kidney, including IL-6 production and activation of STAT3 and ROR $\gamma$ t, demonstrating that this molecular mechanism is operating in CCN2(IV)-induced renal damage and it could underlie the observed activation of the local Th17 response.
In contrast, no changes in renal levels of Th1/Th2 cytokines or Treg-related factors such as TGF- $\beta$ and Foxp-3 were found, suggesting that Th1/Th2/Treg responses were not modulated by CCN2(IV), at least in the murine kidney.

Recent studies have shown the importance of Th17 cells, and its hallmark cytokine IL-17A, in immunemediated glomerulonephritis, including experimental antimyeloperoxidase glomerulonephritis, crescentic glomerulonephritis, and lupus nephritis. ${ }^{46,47}$ The direct involvement of Th17 cells in renal damage has been demonstrated by an experimental study in mice, showing that injection of Th17 cells resulted in developed albuminuria after 3 days, glomerular neutrophil infiltration, and increased renal CXCL1 mRNA. ${ }^{48}$ In the kidney of CCN2(IV)-treated mice, infiltrating Th17 cells were detected by double $\mathrm{CD}^{+}$/ IL-17A ${ }^{+}$staining, suggesting that Th17 cells could contribute to renal damage by $\mathrm{CCN} 2(\mathrm{IV})$. 

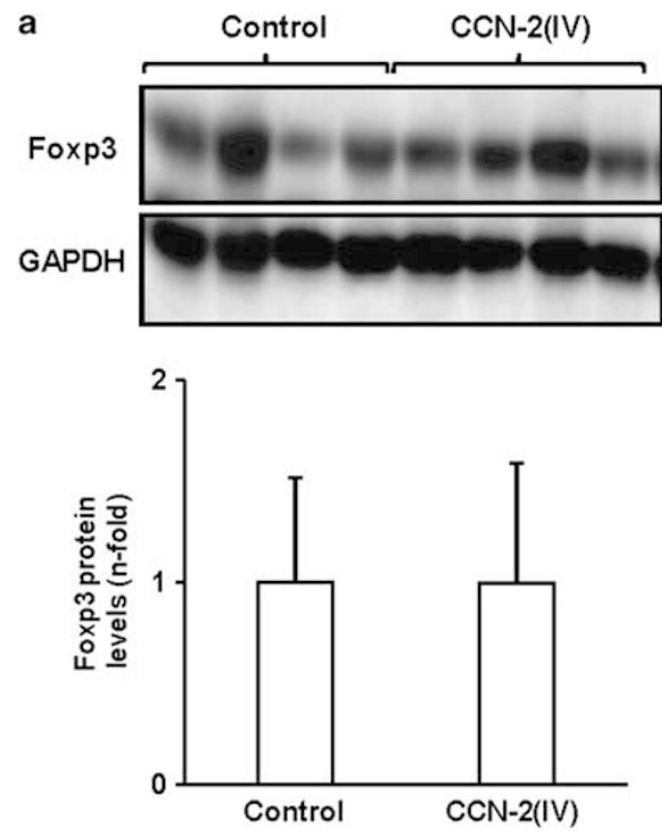

b

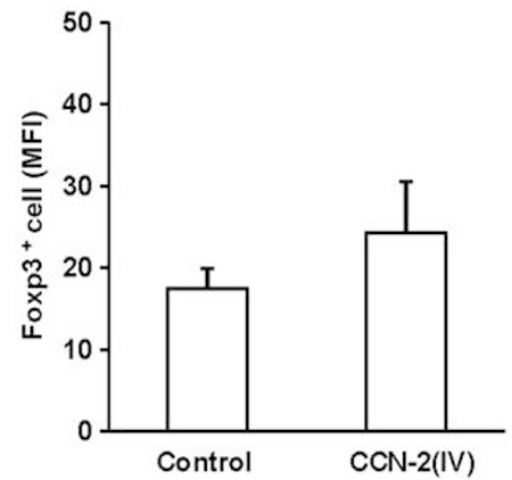

Figure 8 CCN2(IV) did not regulate Treg-related transcription factors. Foxp3 renal levels were analyzed by western blot. (a) Data as ratio of renal Foxp3/GAPDH protein as mean \pm s.e.m. of 10 mice per group and a representative western blot experiment. Treg $\left(\mathrm{CD}^{+}{ }^{+} \mathrm{Foxp} 3^{+}\right)$cells were analyzed in plasma by flow cytometry. (b) The percentage of $\mathrm{CD}^{+}$ $T$ cells expressing Foxp3 cells (mean \pm s.e.m. of 10 mice per group). ${ }^{*} P<0.05$ vs control.

Besides Th17 cells, IL-17A can be produced by other cells, including $\mathrm{CD} 8^{+} \mathrm{T}$ cells, $\gamma \delta \mathrm{T}$ cells, natural killer cells, neutrophils, and some resident cells. ${ }^{49}$ In the model of ischemiareperfusion, neutrophils, but not Th17 cells, are the main sources of IL-17A and contribute to renal injury by natural killer $\mathrm{T}$ activation and IL-12/IFN- $\gamma$ production. ${ }^{50}$ In glomeruli of patients with lupus nephritis, double-negative (CD4, CD8) T cells are a major source of IL-17A, ${ }^{51}$ and in renal allograft rejection, positive staining for IL-17A has been detected in tubular cells, ${ }^{41}$ as we have observed here in CCN2(IV)-treated mice, suggesting that renal cells could produce this cytokine and contribute to extend the damage.

The biological actions of IL-17A are predominantly proinflammatory. ${ }^{49}$ There are several pathways by which this

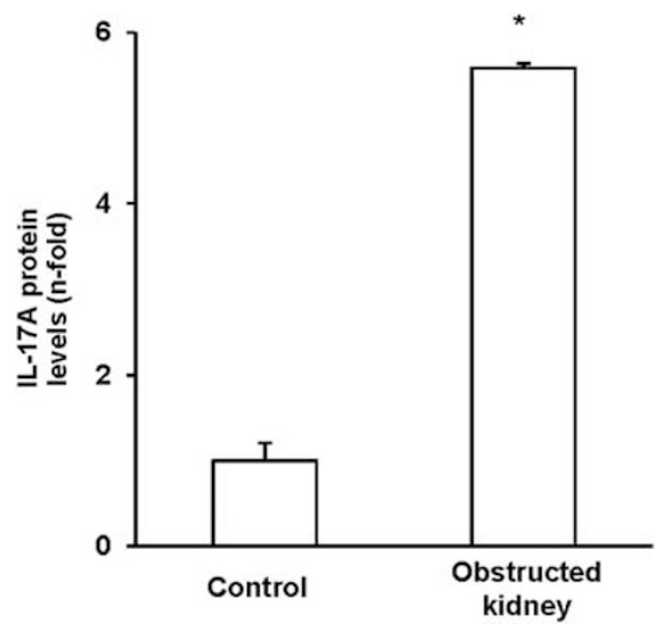

Figure 9 Upregulation of renal levels of IL-17A in the model of unilateral ureteral obstruction in mice. IL-17A renal levels were evaluated by ELISA and expressed as data as mean \pm s.e.m. of 6 animals per group. ${ }^{*} P<0.05$ vs control mice.

cytokine might affect local inflammation. In tubular cells, mesangial cells, vascular smooth muscle cells, endothelial cells, and fibroblasts, IL-17A induces the release of cytokines and chemokines such as IL-16, MCP-1, RANTES, CXCL1, and CXCL8 that recruit different leukocyte subsets leading to target organ injury. ${ }^{52}$ IL-17A can also directly promote monocyte chemotaxis..$^{53}$ Our in vitro and in vivo data clearly show that CCN2(IV) induces IL-17A production. In CCN2(IV)-injected mice, renal overexpression of IL-17A was associated with the presence of inflammatory infiltrating cells and upregulation of chemokines that were reduced in IL-17A neutralization experiments, clearly demonstrating the involvement of IL-17A in CCN2(IV)-mediated renal inflammation. Studies in knockout mice have shown that the absence of IL-17A resulted in less glomerular crescent formation and improved renal function in experimental nephrotoxic nephritis. ${ }^{54}$ Several IL-17A blockade strategies, including neutralizing antibodies or receptor gene targeting, ameliorated several experimental nonimmune diseases. ${ }^{32-36}$ Preliminary data in rheumatoid arthritis and uveitis, ${ }^{34}$ and more recently, data from two phase 2 clinical trials, in which patients with psoriasis were treated with specific targeting antibodies for IL-17A or its receptor, ${ }^{35,36}$ have shown beneficial effects in humans. CCN2 has been involved in several chronic diseases, including skin disorders, cardiac hypertrophy, atherosclerosis, pulmonary hypertension, and lung and liver diseases, ${ }^{12}$ where IL-17A is a key player. $^{32,33,55-58}$ In the nonimmune murine model of UUO, we have observed elevated renal levels of IL-17A and infiltrating inflammatory cells associated with renal $\mathrm{CCN} 2$ overexpression. Although future studies are needed, our data showing that IL-17A blockade ameliorated CCN2-induced renal inflammation support the concept of 
IL-17A-neutralizing antibody as a promising tool for chronic inflammatory diseases, including chronic kidney diseases.

CCN2 overexpression has been described in human fibrotic diseases, and it is produced temporally and spatially in close proximity to fibrotic areas. ${ }^{2,12}$ Antagonists of CCN2 have proven effective in blocking profibrogenic CCN2 signaling pathways in vitro and have yielded promising data with respect to preventing experimental fibrosis. ${ }^{14}$ Regarding renal diseases, knockdown of CCN2 gene expression with antisense gene transfer into rat kidney ameliorates tubulointerstitial fibrosis in obstructive nephropathy ${ }^{14}$ and in experimental mice diabetes in C57BL/6 mice. ${ }^{16}$ CCN2 is known to function downstream of TGF- $\beta$, driving extracellular matrix accumulation and fibrosis. ${ }^{2,12}$ Indeed, in cultured renal cells, CCN2 blockade diminished matrix proteins synthesis induced by TGF- $\beta$ and Angiotensin II. ${ }^{59}$ Although initial studies in fibroblasts, and other cultured cells, showed that recombinant $\mathrm{CCN} 2$, both the C-terminal and the full molecule, induce extracellular matrix production, $2,7,14$ several in vivo studies have shown that CCN2 alone is not sufficient to cause ongoing fibrotic changes. In a model of a skin fibrosis, injection of CCN2 alone did not induce fibrosis and only the simultaneous application of TGF- $\beta 1$ caused persistent fibrosis. ${ }^{60}$ CCN2 overexpression in rat lungs only caused a temporal induction of procollagen gene expression and transient matrix accumulation, but it is not sufficient to induce progressive fibrosis. ${ }^{61}$ Podocyte-specific CCN2-transgenic mice (in C57BL/6 background) exhibited no glomerular abnormalities, proteinuria, or matrix accumulation, although they were more susceptible to streptozotocin-induced diabetes. ${ }^{62}$ Our in vivo data showed a similar response in the kidney. Systemic CCN2(IV) administration into C57BL/6 mice increased profibrotic genes renal expression at day 5, and decreasing thereafter, and no collagen accumulation was observed.

Our findings expand the known profibrogenic CCN2 signaling pathways to a true cytokine with an active role in sustained renal inflammation mediated by Th17 cells. Different strategies for blocking CCN2 activity have proven beneficial effects in fibrotic-related pathologies, including renal diseases, ${ }^{12}$ whereas CCN2 overexpression induces cardioprotection. ${ }^{17,18}$ Our results set out that IL17A neutralization block inflammatory events caused by the C-terminal module of CCN2 in the kidney, and suggest that IL-17A targeting could be a better therapeutic option than CCN2 blockers for human use in inflammatory diseases.

\section{ACKNOWLEDGEMENTS}

We thank $M^{a}$ Mar Gonzalez Garcia-Parreño for her technical

help with confocal microscopy, and Susana Carrasco for her help in immunohistochemical procedures. Grant numbers and sources of support are as follows: grants from the Instituto de Salud Carlos III (ISCIII-RETIC RD06/0016 y RD0012/0021, REDINREN, PI081564, PI11/01854, PI12/02587, PI10/00072, PI12/00204 and PS09/00447), Comunidad de Madrid (S2010/ BMD-2321), Sociedad Española de Nefrología, Fundación Lilly, Research Institute Queen Sophia (FRIAT), Programa Intensificación Actividad
Investigadora (ISCIII/Agencia Laín-Entralgo/CM) to AO, RR-D, ES-L, CL, and MA, who are fellows of ISCIII.

\section{DISCLOSURE/CONFLICT OF INTEREST}

The authors declare no conflict of interest.

1. Winter $\mathrm{P}$, Leoni $\mathrm{P}$, Abraham $\mathrm{D}$. Connective tissue growth factor: structure-function relationships of a mosaic, multifunctional protein. Growth Factors 2008;26:80-91.

2. Phanish MK, Winn SK, Dockrell ME. Connective tissue growth factor(CTGF, CCN2)-a marker mediator and therapeutic target for renal fibrosis. Nephron Exp Nephrol 2010;114:e83-e92.

3. Hashimoto G, Inoki I, Fujii $\mathrm{Y}$, et al. Matrix metalloproteinases cleave connective tissue growth factor and reactivate angiogenic activity of vascular endothelial growth factor 165. J Biol Chem 2002;277:36288-36295.

4. Brigstock DR, Steffen CL, Kim GY, et al. Purification and characterization of novel heparin-binding growth factors in uterine secretory fluids. Identification as heparin-regulated Mr 10,000 forms of connective tissue growth factor. J Biol Chem 1997;272:20275-20282.

5. O'Seaghdha CM, Hwang SJ, Bhavsar NA, et al. Lower urinary connective tissue growth factor levels and incident CKD stage 3 in the general population. Am J Kidney Dis 2011;57:841-849.

6. Nguyen $T Q$, Tarnow $L$, Andersen $S$, et al. Urinary connective tissue growth factor excretion correlates with clinical markers of renal disease in a large population of type 1 diabetic patients with diabetic nephropathy. Diabetes Care 2006;29:83-88.

7. Slagman MC, Nguyen TQ, Waanders $F$, et al. Clin Effects of antiproteinuric intervention on elevated connective tissue growth factor (CTGF/CCN2) plasma and urine levels in nondiabetic nephropathy. J Am Soc Nephrol 2011;6:1845-1850.

8. Riser BL, Cortes P, DeNichilo M, et al. Urinary CCN2 (CTGF) as a possible predictor of diabetic nephropathy: preliminary report. Kidney Int 2003;64:451-458.

9. Tam FW, Riser BL, Meeran K, et al. Urinary monocyte chemoattractant protein-1 (MCP-1) and connective tissue growth factor (CCN2) as prognostic markers for progression of diabetic nephropathy. Cytokine 2009:47:37-42.

10. Bao J, Tu Z, Wang J, et al. A novel accurate rapid ELISA for detection of urinary connective tissue growth factor, a biomarker of chronic allograft nephropathy. Transplant Proc 2008;40:2361-2364.

11. Koitabashi N, Arai M, Niwano K, et al. Plasma connective tissue growth factor is a novel potential biomarker of cardiac dysfunction in patients with chronic heart failure. Eur J Heart Fail 2008;10:373-379.

12. Leask A, Parapuram SK, Shi-Wen X, et al. Connective tissue growth factor (CTGF, CCN2) gene regulation: a potent clinical bio-marker of fibroproliferative disease? J Cell Commun Signal 2009;3:89-94.

13. Ruiz-Ortega M, Rodríguez-Vita J, Sanchez-Lopez E, et al. TGF-beta signaling in vascular fibrosis. Cardiovasc Res 2007;74:196-206.

14. Yokoi $\mathrm{H}$, Mukoyama $\mathrm{M}$, Nagae $\mathrm{T}$, et al. Reduction in connective tissue growth factor by antisense treatment ameliorates renal tubulointerstitial fibrosis. J Am Soc Nephrol 2004;15:1430-1440.

15. Okada H, Kikuta T, Kobayashi T, et al. Connective tissue growth factor expressed in tubular epithelium plays a pivotal role in renal fibrogenesis. J Am Soc Nephrol 2005;16:133-143.

16. Guha $M, X u Z G$, Tung $D$, et al. Specific down-regulation of connective tissue growth factor attenuates progression of nephropathy in mouse models of type 1 and type 2 diabetes. FASEB J 2007;21:3355-3368.

17. Panek AN, Posch MG, Alenina N, et al. Connective tissue growth factor overexpression in cardiomyocytes promotes cardiac hypertrophy and protection against pressure overload. PLoS One 2009;4:e6743.

18. Ahmed MS, Gravning J, Martinov VN, et al. Mechanisms of novel cardioprotective functions of CCN2/CTGF in myocardial ischemiareperfusion injury. Am J Physiol Heart Circ Physiol 2011;300: H1291-H1302.

19. Kular L, Pakradouni J, Kitabgi $P$, et al. The CCN family: a new class of inflammation modulators? Biochimie 2011;93:377-388.

20. Cicha I, Yilmaz A, Klein $M$, et al. Connective tissue growth factor is overexpressed in complicated atherosclerotic plaques and induces mononuclear cell chemotaxis in vitro. Arterioscler Thromb Vasc Biol 2005;25:1008-1013. 
21. Sánchez-López E, Rayego S, Rodrigues-Díez R, et al. CTGF promotes inflammatory cell infiltration of the renal interstitium by activating NF-kappaB. J Am Soc Nephrol 2009;20:1513-1526.

22. Liu BC, Zhang JD, Zhang XL, et al. Role of connective tissue growth factor (CTGF) module 4 in regulating epithelial mesenchymal transition in HK-2 cells. Clin Chim Acta 2006;373:144-150.

23. Markiewicz M, Nakerakanti SS, Kapanadze B, et al. Connective tissue growth factor (CTGF/CCN2) mediates angiogenic effect of S1P in human dermal microvascular endothelial cells. Microcirculation 2011;18:1-11.

24. Sánchez-López E, Rodriguez-Vita J, Cartier C, et al. Inhibitory effect of interleukin-1beta on angiotensin Il-induced connective tissue growth factor and type IV collagen production in cultured mesangial cells. Am J Physiol Renal Physiol 2008;294:F149-F160.

25. Wang X, McLennan SV, Allen TJ, et al. Regulation of pro-inflammatory and pro-fibrotic factors by CCN2/CTGF in H9c2 cardiomyocytes. J Cell Commun Signal 2010;4:15-23.

26. Kim HS, Nagalla SR, Oh $\mathrm{Y}$, et al. Identification of a family of low-affinity insulin-like growth factor binding proteins (IGFBPs): characterization of connective tissue growth factor as a member of the IGFBP superfamily. Proc Natl Acad Sci USA 1997;94:12981-12986.

27. Lam S, van der Geest RN, Verhagen NA, et al. Connective tissue growth factor and IGF-I are produced by human renal fibroblasts and cooperate in the induction of collagen production by high glucose. Diabetes 2003;52:2975-2983.

28. Chen Y, Abraham DJ, Shi-Wen X, et al. CCN2 (connective tissue growth factor) promotes fibroblast adhesion to fibronectin. Mol Biol Cell 2004; 15:5635-5646.

29. Chang CC, Shih JY, Jeng YM, et al. Connective tissue growth factor and its role in lung adenocarcinoma invasion and metastasis. J Natl Cancer Inst 2004:96:364-375.

30. Bettelli $E$, Korn T, Oukka $M$, et al. Induction and effector functions of $\mathrm{T}(\mathrm{H}) 17$ cells. Nature 2008;453:1051-1057.

31. Harrington LE, Hatton RD, Mangan PR, et al. Interleukin 17-producing $\mathrm{CD}^{+}{ }^{+}$effector $\mathrm{T}$ cells develop via a lineage distinct from the $\mathrm{T}$ helper type 1 and 2 lineages. Nat Immunol 2005;6:1123-1132.

32. Erbel C, Chen L, Bea F, et al. Inhibition of IL-17A attenuates atherosclerotic lesion development in apoE-deficient mice. J Immunol 2009;183:8167-8175.

33. Smith $E$, Prasad KM, Butcher $M$, et al. Blockade of interleukin-17A results in reduced atherosclerosis in apolipoprotein E-deficient mice. Circulation 2010;121:1746-1755.

34. Hueber W, Patel DD, Dryja T, et al. Effects of AIN457, a fully human antibody to interleukin-17A, on psoriasis, rheumatoid arthritis, and uveitis. Sci Transl Med 2010;252ra72.

35. Leonardi $C$, Matheson $\mathrm{R}$, Zachariae $\mathrm{C}$, et al. Anti-interleukin-17 monoclonal antibody ixekizumab in chronic plaque psoriasis. $\mathrm{N}$ Engl J Med 2012;366:1190-1199.

36. Papp KA, Leonardi C, Menter A, et al. Brodalumab, an anti-interleukin17-receptor antibody for psoriasis. N Engl J Med 2012;366:1181-1189.

37. Esteban V, Lorenzo O, Rupérez M, et al. Angiotensin II, via AT1 and AT2 receptors and NF-kappaB pathway, regulates the inflammatory response in unilateral ureteral obstruction. J Am Soc Nephrol 2004;15:1514-1529.

38. Das J, Ren G, Zhang L, et al. Transforming growth factor beta is dispensable for the molecular orchestration of Th17 cell differentiation. J Exp Med 2009;206:2407-2416.

39. Mathur AN, Chang HC, Zisoulis DG, et al. Stat3 and Stat4 direct development of IL-17-secreting Th cells. J Immunol 2007;178:4901-4907.

40. Ivanov II, McKenzie BS, Zhou L, et al. The orphan nuclear receptor RORgammat directs the differentiation program of proinflammatory IL-17 + T helper cells. Cell 2006;126:1121-1133.
41. Loverre A, Tataranni T, Castellano G, et al. IL-17 expression by tubular epithelial cells in renal transplant recipients with acute antibodymediated rejection. Am J Transplant 2011;11:1248-1259.

42. Chung AC, Lan HY. Chemokines in renal injury. J Am Soc Nephrol 2011;22:802-809.

43. Sanz AB, Sanchez-Niño MD, Ramos AM, et al. NF-kappaB in renal inflammation. J Am Soc Nephrol 2010;21:1254-1262.

44. Hori S, Nomura T, Sakaguchi S. Control of regulatory $T$ cell development by the transcription factor Foxp3. Science 2003;299:1057-1061.

45. Dong $X$, Bachman LA, Miller MN, et al. Dendritic cells facilitate accumulation of IL-17 T cells in the kidney following acute renal obstruction. Kidney Int 2008;74:1294-1309.

46. Turner JE, Paust HJ, Steinmetz OM, et al. The Th17 immune response in renal inflammation. Kidney Int 2010;77:1070-1075.

47. Kitching AR, Holdsworth SR. The emergence of Th17 cells as effectors of renal injury. J Am Soc Nephrol 2011;22:235-238.

48. Summers SA, Steinmetz OM, Li M, et al. Th1 and Th17 cells induce proliferative glomerulonephritis. J Am Soc Nephrol 2009;20: 2518-2524.

49. Gaffen SL. Structure and signalling in the IL-17 receptor family. Nat Rev Immunol 2009;9:556-567.

50. Li L, Huang L, Vergis AL, et al. IL-17 produced by neutrophils regulates IFN-gamma-mediated neutrophil migration in mouse kidney ischemia-reperfusion injury. J Clin Invest 2010;120:331-342.

51. Crispin JC, Oukka M, Bayliss G, et al. Expanded double negative T cells in patients with systemic lupus erythematosus produce IL-17 and infiltrate the kidneys. J Immunol 2008;181:8761-8766.

52. Van Kooten C, Boonstra JG, Paape ME, et al. Interleukin-17 activates human renal epithelial cells in vitro and is expressed during renal allograft rejection. J Am Soc Nephrol 1998;9:1526-1534.

53. Shahrara S, Pickens SR, Dorfleutner A, et al. IL-17 induces monocyte migration in rheumatoid arthritis. J Immunol 2009;182: 3884-3891.

54. Paust HJ, Turner JE, Steinmetz OM, et al. The IL-23/Th17 axis contributes to renal injury in experimental glomerulonephritis. J Am Soc Nephrol 2009;5:969-979.

55. Guttman-Yassky E, Nograles KE, Krueger JG. Contrasting pathogenesis of atopic dermatitis and psoriasis-part II: immune cell subsets and therapeutic concepts. J Allergy Clin Immunol 2011;127: 1420-1432.

56. Nembrini C, Marsland BJ, Kopf M. IL-17-producing T cells in lung immunity and inflammation. J Allergy Clin Immunol 2009;123: 986-994.

57. Booth AJ, Bishop DK. TGF- $\beta$, IL-6, IL-17 and CTGF direct multiple pathologies of chronic cardiac allograft rejection. Immunotherapy 2010;2:511-520

58. Hammerich L, Heymann F, Tacke F. Role of IL-17 and Th17 cells in live diseases. Clin Dev Immunol 2011;2011:345803.

59. Rupérez M, Lorenzo O, Blanco-Colio LM, et al. Connective tissue growth factor is a mediator of angiotensin II-induced fibrosis. Circulation 2003;108:1499-1505.

60. Mori T, Kawara S, Shinozaki M, et al. Role and interaction of connective tissue growth factor with transforming growth factor-beta in persistent fibrosis: a mouse fibrosis model. J Cell Physio 1999;181:153-159.

61. Bonniaud $P$, Margetts PJ, Kolb $M$, et al. Adenoviral gene transfer of connective tissue growth factor in the lung induces transient fibrosis. Am J Respir Crit Care Med 2003;168:770-778.

62. Yokoi H, Mukoyama M, Mori K, et al. Overexpression of connective tissue growth factor in podocytes worsens diabetic nephropathy in mice. Kidney Int 2008;73:446-455. 